\title{
Editorial from the New Editor-in-Chief
}

ACM Transactions on Modeling and Computer Simulation (TOMACS) is the journal that offered me articles to read and study at the very beginning of my activity related to simulation methods, algorithms, and systems. It has been my reference for a long time, and I am extremely honored to write this editorial as the new Editor-in-Chief (EIC) of this journal. TOMACS is known to publish excellent research results in many areas, covering a very wide set of topics. It is an extremely interdisciplinary journal that allows theory and practice to meet. This achievement has been possible thanks to the hard work of many persons, including past editors and all the members of the editorial board. I am glad to take the opportunity to continue their work.

Nowadays, it is common to use modeling methods and simulation systems to devise strategies, to make critical decisions, and to drive the evolution of processes that affect our lives. Hence, further increasing the visibility of TOMACS across research communities, as well as widening its scope and impact, is a core target I will pursue. I am sure all the members of the editorial board will sustain me and will take an active role in the organization of journal issues, which will include extended versions of articles that have been early scouted as top-quality ones in well-known conferences or other excellent venues. Furthermore, it is my objective to additionally strengthen the linkage between TOMACS and conferences that have traditionally, or more recently, offered the support for thematic (although not narrow) special issues.

I will welcome high-quality surveys providing an assessment of the state of the art and pointing to challenging research directions.

Thanks to the big effort by the previous EIC Adelinde Uhrmacher, TOMACS has started being involved in the important process of Reproducibility of Computational Results (RCR). This process further qualifies the research results published in the journal by guaranteeing a more direct and fruitful re-usability of results across researchers. I will sustain the involvement of TOMACS in RCR by encouraging authors of submitted articles to participate in this initiative.

Rigorously managing the review process is an additional target I will pursue, with the objective of combining high quality of the reviews with speed in the evaluation of the submitted articles. Timeliness in the diffusion of relevant research results will be of crucial importance for the TOMACS community, as well as for all the communities that can take advantage of these results for stepping ahead in their research paths and achievements. In the end, we will all benefit from it.

For sure, handling TOMACS as EIC will be a challenge, in which I will put as much passion as I can.

January 2020

Francesco Quaglia

Editor-in-Chief

(c) 2020 Association for Computing Machinery.

1049-3301/2020/02-ART1e

https://doi.org/10.1145/3377148 